\title{
Association between Socioeconomic Status, Salivary Streptococcus mutans, Lactobacilli and Dental Caries among 12-Year-Old School Children in Belgaum City
}

\author{
${ }^{1}$ Mamata Iranna Hebbal, ${ }^{2}$ Anil V Ankola, ${ }^{3}$ Sharada C Metgud \\ ${ }^{1}$ Reader and PhD Scholar, Department of Public Health Dentistry, KLE VK Institute of Dental Sciences, Belgaum, Karnataka, India \\ ${ }^{2}$ Professor and Head, Department of Public Health Dentistry, KLE VK Institute of Dental Sciences, Belgaum, Karnataka, India \\ ${ }^{3}$ Professor and Former Head, Department of Microbiology, Jawaharlal Nehru Medical College, Belgaum, Karnataka, India
}

Correspondence: Mamata Iranna Hebbal, Reader and PhD Scholar, Department of Public Health Dentistry, KLE VK Institute of Dental Sciences, Belgaum Karnataka, India, Phone: 09844217300, e-mail: drmamatahebbal@rediffmail.com

\section{ABSTRACT}

Introduction: Aim of the study was to assess dental caries using Modified Dentition Status and Treatment Needs and find its association with salivary Streptococcus mutans and lactobacilli counts among 12-year-old school children of Belgaum city.

Materials and methods: A self-designed, 13 item, open-ended questionnaire given to parents. Children were examined for dental caries using Modified Dentition Status and Treatment Needs. Stimulated saliva was collected and incubated to estimate lactobacilli and Streptococcus mutans colonies. Chi-square test was used to find the association between variables.

Results: When DMFT was recorded it was found that $23 \%$ of children were free from dental caries, whereas, only $5 \%$ of them were free of dental caries when examined using modified criteria. Most of the children had higher microbial count with $72 \%$ and $62 \%$ of them having $>10^{5} \mathrm{cfu} / \mu \mathrm{l}$ of Streptococcus mutans and lactobacilli colony count respectively. Modified DMFT was significantly associated with frequency of brushing, lactobacilli and Streptococcus mutans counts $(p<0.05)$.

Conclusion: The proportion of subjects with dental caries was relatively high in all groups but the number of teeth affected by caries was low. Inclusion of noncavitated incipient lesions could increase sensitivity of index.

Keywords: Dental caries, Socioeconomic status, Streptococcus mutans, lactobacilli colony counts.

\section{INTRODUCTION}

Dental caries ranks amongst the most common of human diseases simply because of its frequency of occurrence. Although the severity of the dental disease in terms of its life threatening potential is limited except in rare instances, certain important consequences must be stressed. Treatment of dental caries is costly both in terms of time and money. ${ }^{1}$ Dental caries and its sequel often involve pain and have effects on esthetics. Dental caries is often seen as a multifactorial disease with interplay of microorganisms, dietary factors and salivary composition. Socioeconomic background has an indirect influence on pathogenesis of caries development since factors like type of diet taken, oral hygiene practices, use of fluoride and other preventive measures and dental visits are dependent on socioeconomic status. Many studies showed dental caries to be connected with social deprivation. ${ }^{2-6}$ The influence of the socioeconomic status on oral health varies considerably between countries. There is considerable evidence about the role of the Streptococcus mutans and lactobacilli in caries initiation and development of caries lesion and they can be considered as caries risk indicators. ${ }^{7,8}$ Although many Indian studies are published on prevalence of dental caries, studies on relation with microorganism are sparse, hence, the present study was planned with an aim to assess dental caries using modified dentition status and treatment needs and find its association with salivary Streptococcus mutans and lactobacilli counts.

\section{METHODOLOGY}

The present study was conducted among 12-year-old school children of Belgaum city which is the district headquarters located in northern part of Karnataka. It is a part of a longitudinal study being conducted to assess the effect of preventive measures on caries risk. Permission to conduct the study was obtained from Deputy Director of Public Instructions (DDPI) and school authorities. Ethical clearance was also obtained from Institutional Review Board (IRB). A total of four schools out of 285 schools were randomly selected for the study. Informed consent and assent was obtained from parents and children respectively.

A self-designed, 13 item open-ended questionnaire, which consisted of details of personal information like name, gender, age, oral hygiene practices and sociodemographic details was translated in local languages (Kannada and Marathi) by the experts well versed in the particular languages. Retranslation to English was done by another expert to check the accuracy of translation. Socioeconomic status was assessed using Kuppuswamy 
socioeconomic classification which takes into account education, occupation and income. ${ }^{9}$ Children with mixed dentition were excluded from the study after screening for inclusion criteria. The parents who gave informed consent were asked to complete the questionnaire and instructions to be followed while filling were also given.

Clinical examination and saliva collection was done at the school premises under natural lighting conditions with a single trained assistant who recorded the findings. 20 children were examined per day.

1. Clinical examination: Children were examined for dental caries using modified WHO Dentition Status and Treatment Needs. The initial lesions (WP) were taken into account and all the surfaces were also considered in order to make the index more sensitive. ${ }^{10}$ Examination was done by a single trained and calibrated examiner. The intraexaminer reliability was found to be 0.86 .

2. Saliva collection: Children were asked to chew a modeling wax made into a form of pellet $(0.5 \times 0.5 \mathrm{~cm})$ for 3 minutes to obtain stimulated saliva. By means of a sterile disposable syringe, $0.5 \mathrm{ml}$ aliquot of saliva collected directly from the oral cavity was injected in a previously labeled sterile bottle containing $2 \mathrm{ml}$ of thioglycolate transport medium. The samples were processed on the same day in the Department of Microbiology, Jawaharlal Nehru Medical College.

\section{Laboratory Procedure}

The samples were vortexed to uniformly mix the saliva and the media using a cyclomixer. Using an inoculation loop (standard loop with $4 \mathrm{~mm}$ inner diameter), 10 microliter of the vortexed sample was streaked on Mitis salivarius agar, selective for Streptococcus mutans and on Rogosa SL agar for Lactobacillus. The Mitis salivarius agar plates were incubated in an anaerobic jar for 48 hours at $37^{\circ} \mathrm{C}$ in an incubator and similar procedure were followed for Rogosa SL agar plates, which were incubated for 96 hours. $^{11}$

\section{Statistical Methods}

Data were analyzed using SPSS statistical package (version 17.0 SPSS Inc. Chicago III USA). Descriptive statistics including means and standard deviations were calculated and Chi-square test was used to find the association between variables. p-value $<0.05$ was considered statistically significant.

\section{RESULTS}

A total of 100 children were examined among which $53 \%$ were males and $47 \%$ were females. $25 \%$ and $75 \%$ of them belonged to lower and middle socioeconomic class respectively and none of them were from upper class. Most of the children cleaned their teeth once daily using toothbrush and toothpaste. When

Table 1: Distribution of study population according to gender, SES, DMFT and microbial counts

\begin{tabular}{|c|c|c|c|}
\hline S. No. & Variables & & Percentage \\
\hline 1. & Gender & $\begin{array}{l}\text { Male } \\
\text { Female }\end{array}$ & $\begin{array}{l}53 \\
47\end{array}$ \\
\hline 2. & Socioeconomic status & $\begin{array}{l}\text { 1. Lower } \\
\text { 2. Upper lower } \\
\text { 3. Lower middle } \\
\text { 4. Upper middle } \\
\text { 5. Upper }\end{array}$ & $\begin{array}{r}5 \\
20 \\
54 \\
21 \\
0\end{array}$ \\
\hline 3. & $\begin{array}{l}\text { Modified socioeconomic status } \\
\text { ( } 1 \& 2 \text { and } 3 \& 4 \text { are combined) }\end{array}$ & $\begin{array}{l}\text { Lower } \\
\text { Middle } \\
\text { Upper }\end{array}$ & $\begin{array}{r}25 \\
75 \\
0\end{array}$ \\
\hline 4. & Method of oral hygiene practice & $\begin{array}{l}\text { Toothbrush } \\
\text { Finger }\end{array}$ & $\begin{array}{r}99 \\
1\end{array}$ \\
\hline 5. & Materials used & $\begin{array}{l}\text { Toothpaste } \\
\text { Tooth powder }\end{array}$ & $\begin{array}{r}99 \\
1\end{array}$ \\
\hline 6. & Frequency & $\begin{array}{l}\text { Twice daily } \\
\text { Once daily }\end{array}$ & $\begin{array}{l}26 \\
74\end{array}$ \\
\hline 7. & DMFT & $\begin{array}{l}\text { DMFT- } 0 \\
\text { DMFT >0 }\end{array}$ & $\begin{array}{l}23 \\
77\end{array}$ \\
\hline 8. & WPDMFT & $\begin{array}{l}\text { WPDMFT- } 0 \\
\text { WPDMFT >0 }\end{array}$ & $\begin{array}{r}5 \\
95\end{array}$ \\
\hline 9. & Streptococcus mutans colony count & $\begin{array}{l}\text { 0-negligible } \\
1<10^{4} \mathrm{CFU} / \mathrm{Ml} \\
2-10^{4}-10^{5} \mathrm{CFU} / \mathrm{Ml} \\
3>10^{5} \mathrm{CFU} / \mathrm{Ml}\end{array}$ & $\begin{array}{r}0 \\
0 \\
28 \\
72\end{array}$ \\
\hline 10. & Lactobacilli colony count & $\begin{array}{l}0<10^{3} \mathrm{CFU} / \mathrm{Ml} \\
1-10^{4} \mathrm{CFU} / \mathrm{Ml} \\
2-10^{5} \mathrm{CFU} / \mathrm{Ml} \\
3>10^{6} \mathrm{CFU} / \mathrm{Ml}\end{array}$ & $\begin{array}{r}4 \\
33 \\
62 \\
1\end{array}$ \\
\hline
\end{tabular}


Table 2: Distribution of study population according to various DMFT values

\begin{tabular}{|c|c|c|c|c|c|c|}
\hline & & \multicolumn{3}{|c|}{$D M F T$} & \multicolumn{2}{|c|}{ DMFS } \\
\hline & & Mean & & $S D$ & Mean & $S D$ \\
\hline \multicolumn{2}{|c|}{ Initial noncavitated active lesions (WP) } & 2.33 & & 1.76 & 2.52 & 1.90 \\
\hline \multicolumn{2}{|c|}{ Cavitated active lesions (1W) } & 2.21 & & 2.09 & 2.83 & 3.26 \\
\hline \multicolumn{2}{|c|}{ Cavitated inactive lesions (1) } & 0.47 & & 0.79 & 0.60 & 1.02 \\
\hline \multicolumn{2}{|c|}{ DT/DS } & 2.68 & & 1.64 & 3.43 & 2.14 \\
\hline \multicolumn{2}{|l|}{ MT/MS } & 0.01 & & 0.10 & 0.05 & 0.50 \\
\hline \multicolumn{2}{|l|}{ FT/FS } & 0.00 & & 0.00 & 0.00 & 0.00 \\
\hline \multicolumn{2}{|l|}{ DMFT/DMFS } & 2.69 & & 2.34 & 3.48 & 3.62 \\
\hline \multicolumn{2}{|l|}{$\begin{array}{l}\text { DMFT + WP/DMFS + WP } \\
\text { (including initial lesions) }\end{array}$} & 5.01 & & 2.46 & 5.98 & 3.63 \\
\hline DMFT vs DMFT + WP & $t-6.82$ & df-198 & $p<0.001$ & & & \\
\hline DMFS vs DMFS + WP & $\mathrm{t}-4.868$ & df-198 & $p<0.001$ & & & \\
\hline
\end{tabular}

Table 3: Association between different variables Chi-square test

\begin{tabular}{clllll} 
S.No. & Variables & $\chi^{2}$ value & $d f$ & $p$-value & Significance \\
\hline 1. & Frequency of tooth brushing and DMFT & $\chi^{2}=7.27$ & $\mathrm{df}=1$ & $\mathrm{p}=0.007$ & Sig \\
2. & Lactobacilli count and DMFT + WP & $\chi^{2}=18.68$ & $\mathrm{df}=3$ & $\mathrm{p}<0.001$ & $\mathrm{HS}$ \\
3. & Streptococus mutans count and DMFT + WP & $\chi^{2}=7.05$ & $\mathrm{df}=1$ & $\mathrm{p}=0.008$ & $\mathrm{Sig}$ \\
4. & SES and DMFT & $\chi^{2}=0.47$ & $\mathrm{df}=1$ & $\mathrm{p}=0.49$ & $\mathrm{NS}$ \\
5. & SES and Lactobacilli count & $\chi^{2}=2.18$ & $\mathrm{df}=3$ & $\mathrm{p}=0.53$ & $\mathrm{NS}$
\end{tabular}

Sig: Significant; HS: Highly significant; NS: Not significant

DMFT was recorded it was found that $23 \%$ of children were free from dental caries whereas only $5 \%$ of them were free of dental caries when examined using modified criteria to include initial non cavitated lesions. Most of the children had higher microbial count with $72 \%$ of them having $>10^{5} \mathrm{CFU} / \mu \mathrm{l}$ of Streptococcus mutans colony count and $62 \%$ of them having $>10^{5} \mathrm{CFU} / \mu \mathrm{l}$ of lactobacilli colony count (Table 1 ).

Detailed description of DMFT status is shown in Table 2. When DMFT and DMFS were compared with their modified counterparts using unpaired t-test, statistically significant difference was found reflecting high sensitivity of modified index. When DMFT was converted into dichotomous values (i.e. dental caries absent and present) and was compared with different variables, it was found that modified DMFT was significantly associated with frequency of brushing, lactobacilli and Streptococcus mutans counts whereas no association was observed between socioeconomic status and DMFT, lactobacilli and Streptococcus mutans counts (Table 3).

\section{DISCUSSION}

The present study was conducted among 12-year-old Belgaum children to find the association between dental caries, socioeconomic status, lactobacilli count and Streptococcus mutans counts. As the aim of the study was to find the utility of this novel index rather than to assess prevalence of dental caries, only four schools with 100 children were thought to be sufficient. The age group of 12-year-old was chosen as this is a WHO global monitoring age for dental caries and only children with permanent dentition were selected in order to avoid discrepancies between mixed and permanent dentition with regard to microbial counts as stated by Schlagenhauf U et al. ${ }^{12}$

Kuppuswamy socioeconomic classification which is the most widely used classification for Indian population was considered in the present study. Kuppuswamy socioeconomic classification although considers most of the parameters required to assess SES, does not consider total number of family members which may sometimes give misleading results. Five social classes were clubbed and made into three classes as there were few children in lower class and no children in upper class. Public/private school attendance may be considered a surrogate measure for socioeconomic status with private school attendance likely to represent higher socioeconomic status relative to public school attendance. ${ }^{13}$ In this study since only aided schools were considered majority of them were from middle class. There was no statistically significant difference between the DMFT and various classes. This result is in accordance with Maisga $\mathrm{A}$ $\mathrm{M}$ et $\mathrm{al}^{14}$ who found no evidence of caries being significantly related to social class, although children in the higher classes had more filled teeth. Reviewing studies of caries in older children in African countries and in China, Manji et al ${ }^{15}$ concluded that neither socioeconomic status nor urbanization can be assumed to be a risk factor for dental caries. However, a strong relationship of caries with social background has been found in other recent studies of Dummer et $\mathrm{al}^{16}$ and 
Zukanovic A et al. ${ }^{17}$ The variation in findings may be due to lack of consensus on how to measure SES in a way that would provide a better understanding of how SES contributes to poor oral health. The current methodology relies on measures that are static, such as educational achievement or geographical measure that are subject to the ecological fallacy. The present study failed to show statistically significant difference between DMFT and social classes. It may be due to unequal distribution of the subjects among different SES classes.

Children in the present study had relatively low dental caries expressed as mean DMFT although the prevalence was 77\%. This is in accordance with study conducted by Mascarenhas $\mathrm{AK}^{18}$ who found that $22 \%$ of children were free of dental caries and mean DMFT and DMFS were 2.78 and 4.20 respectively. There were virtually no filled or missing teeth irrespective of the social classes revealing lack of awareness regarding oral health and hence, individual parameter comparison was not done. Noncavitated incipient lesions (WP) were included in diagnosis of dental caries to avoid the possible underestimation of the disease. ${ }^{10,19}$ The exclusion of incipient caries strongly affected both the prevalence of caries and the mean DMFT (Table 2). Studies by Manji and Tikwomwi et al demonstrated as high a prevalence as $76 \%$ and mean DMFT of 2.97 and $60.4 \%$ (1.88), respectively, in 12-year-old children when incipient lesions were included. When incipient lesions were excluded, the respective figures were $26.5 \%$ (0.55) and 23.1\% (0.45). Despite inclusion of incipient dental caries in the diagnosis, good intraexaminer reliability was observed due to meticulous training and calibration of the examiner before conducting the examination. Also only 20 children were examined per day and short relaxation period was given between examinations to prevent examiner fatigue. When DMFT+WP and DMFS+WP were compared, no difference was observed, i.e. there could be underestimation of proximal lesions as no bite radiographs were taken and were not easily visible as occlusal incipient lesions.

Most of the children brushed once daily, using tooth brush and toothpaste which could be attributed to mass media and Indian culture of cleaning teeth in the morning. Frequency of brushing was found to be positively associated with dental caries since brushing before going to bed is more crucial. ${ }^{20}$

Stimulated saliva was collected for microbial assessment using modeling wax made in the form of pellets. In the pilot study, various materials like paraffin wax, chewing-gum base and orthodontic bands were also used to stimulate saliva and children found modeling wax to be more attractive which could be due to the color. Microbial assessment showed no difference in the counts irrespective of the material used for stimulation. Precaution was taken to avoid contamination by direct collection of saliva from the oral cavity through syringe rather than spitting in the cup. The saliva was immediately added to thioglycolate transport medium containing vial and processed on the same day.

The role of Streptococcus mutans in carious lesion development is well known. ${ }^{21}$ Infection with this microorganism has global distribution, and it can be found in almost all people of one population, but its degree varies from high to low. Analysis of salivary Streptococcus mutans level in the present study revealed that majority of them had high values and statistically significant difference was observed between DMFT+ WP scores and Streptococcus mutans level. Similar results have been observed by Zukanovic A et al. ${ }^{17}$ The level of salivary Lactobacillus can be used as the measure of food cariogenicity. In many developed industrialized countries, caries prevalence has decreased, which is primarily attributed to the increased exposure to fluorides and improved oral hygiene techniques. Therefore, diet has become a less important factor in caries prevention. In the study of Burt et al, it is mentioned that sugars may now be less important in caries etiology than in the past, although in the minority of highly susceptible children diet may be more important. ${ }^{22}$ The results of our study showed that about $62 \%$ of children had high levels of Lactobacillus $\left(10^{5} \mathrm{cfu} / \mu \mathrm{l}\right)$ which is in contrast with the studies conducted by Zukanovic A et al ${ }^{17}$ and Hänsel Petersson $\mathrm{G}$ et $\mathrm{al}^{23}$ who observed very low levels of lactobacilli. Statistically significant difference was observed between DMFT+ WP scores and lactobacilli level. Similar results have been observed by Zukanovic A et al. ${ }^{17}$ In this study no differences between levels of Streptococcus mutans and lactobacilli in children considering the socioeconomic background was found.

To conclude, the proportion of subjects with dental caries was relatively high in all groups but the number of teeth affected by caries was low. Inclusion of non cavitated incipient lesions can be used as a more sensitive tool for short-term evaluation of dental caries. No relation between levels of salivary Streptococcus mutans and lactobacilli and socioeconomic status could be found but a direct association was observed for dental caries. However, further studies can be conducted with larger sample size and equal distribution of subjects in each social class to assess the effect of socioeconomic status on dental caries.

\section{ACKNOWLEDGMENTS}

The authors would like to thank Dr Sheetal Harakuni, Assistant Professor, Department of Microbiology for assisting in microbiological work, Dr Sushma Nayak, Lecturer, Dept of Public Health Dentistry, for assisting in manuscript preparation. The authors also wish to thank all the subjects of the study.

\section{REFERENCES}

1. Legler WD, Menaker Lewis. Definition, etiology, epidemiology and clinical implications of dental caries. In the biologic basis of dental caries: an oral biology textbook, 1st ed, Harper and Row publishers Maryland 1980;211-25.

2. Evans RW, Lo EO, Darvell DW. Determinants of variation in dental caries experience in primary teeth of Hong Kong children aged 6-8 years. Community Dent Oral Epidemiol 1993;21:1-3.

3. Jones CM, Woods K, Taylor GO. Social deprivation and tooth decay in Scottish schoolchildren. Health Bull (Edinb) 1997;55:11-15. 
4. Milen A. Role of social class in caries occurrence in primary teeth. Int J Epidemiol 1987;16:252-56.

5. Treasure ET, Dever J. The prevalence of caries in 5-year-old children living in fluoridated and non-fluoridated communities in New Zealand. New Zealand Dental Journal 1992;88:9-13.

6. Watson MR, Horowitz AM, Garcia I, Canto MT. Caries conditions among 2-5 years old immigrant Latino children related to parent's oral health knowledge, opinions and practices. Community Dent Oral Epidemiol 1999;27:8-15.

7. Crossner CG. Variation in human oral lactobacilli following a change in sugar intake. Scand J Dent Res 1984;92:204-10.

8. Loesche WJ. Role of Streptococci mutans in human dental decay. Microbial Rev 1986;50:353-80.

9. Mishra D, Singh HP. Kuppuswamy's socioeconomic status scale: A revision. Indian Journal of Pediatrics 2003;70: 273-74.

10. Assaf AV, De Castro M, Zanin L, Tengan C, Pereira AC. Effect of different diagnostic thresholds on dental caries calibration a 12 month evaluation. Community Dent Oral Epidemiol 2006;34:213-19.

11. Tavanin GL, Petersson GH, Bratthall D. Collection and treatment of the secretion of the minor salivary glands, In: Tenovuo JO(Ed). Human saliva: Clinical chemistry and microbiology, library of congress cataloging-in-publication 1989;26-54.

12. Schlagenhauf U, Rosendahl R. Clinical and microbiological caries-risk parameters at different stages of dental development. J Pedod Spring 1990;14(3):141-43.

13. Elias-Boneta AR, Kebler KC, Gierbolini CC, Vizcarrondo CET, Psoter WJ. Dental caries prevalence of 12 year olds in PuertoRico. Comm Dent Health 2003;20:171-76.

14. Masiga M, Holt RD. The prevalence of dental caries and gingivitis and their relationship to social class amongst nursery school children in Nairobi, Kenya. Int J Paed Dent 1993;3: 135-40.

15. Manji F, Frejeskov O, Baleum V, Luan W, Chen X. The epidemiological features of dental caries in African and Chinese populations: In: Jonhson NW (Ed). Implications for risk assessment risk markers for oral diseases. Dental caries Cambridge: Cambridge University Press 1991;11:62-99.

16. Dummer PMH, Oliver SJ, Hicks R, Kingdon R, Addy M, Shaw WC. Factors affecting the caries experience of a group of children at the ages of 6-12 and 15-16 years. Results of an ongoing epidemiological survey. J Dent 1990;18:37-48.

17. Zukanovic A, Muratbegovic A, Kobaslija S, Markovic N, Ganibegovic M, Beslagic E. Relationships between socioeconomic backgrounds, caries associated microflora and caries experience in 12-year-olds in Bosnia and Herzegovina in 2004. Eur J Paediatr Dent Sep 2008;9(3):118-24.

18. Mascarenhas AK. Determinants of caries prevalence and severity in higher SES Indian children. Community Dent Health June 1999;16(2):107-13.

19. Mazengo CM, Tenovuo J, Hauscn H. Dental caries in relation to diet, saliva and cariogenic microorganisms in Tanzanians of selected age groups. Community Dent Oral Epidemiol 1996;24:169-74.

20. Zaborskis A, Milciuviene S, Narbutaite J, Bendoraitiene E, Kavaliauskiene A. Caries experience and oral health behaviour among 11-13-year-olds: An ecological study of data from 27 European countries, Israel, Canada and USA. Community Dent Health June 2010;27(2):102-08.

21. Loesche WJ. Role of Streptococci mutans in human dental decay. Microbial Rev 1986;50:353-80.

22. Burt BA, Eklund SA, Morgan KJ, et al. The effects of sugars intake and frequency of ingestion on dental caries in a threeyear longitudinal study. J Dent Res 1988;67:1422-29.

23. Hänsel Petersson G, Fure S, Twetman D, Bratthall D. Comparing caries risk factors and caries risk profiles in children and elderly. Assessing caries risk. Swedish Dental Journal Supplement 2003;158:1-23. 